\title{
Non-nucleosidic analogs of nucleic acids
}

\author{
JOLANTA BRZEZIŃSKA $\ddagger$, KATARZYNA ADRYCH-ROŻEK, ZOFIA JAHNZ-WECHMANN, \\ JERZY BORYSKI, WOJCIECH T. MARKIEWICZ $\ddagger$ * \\ Institute of Bioorganic Chemistry, Polish Academy of Sciences, Poznań, Poland \\ *Corresponding author: Wojciech.Markiewicz@ibch.poznan.pl
}

All the authors contributed to the writing of the manuscript and have given their approval to the final version of the manuscript. $\ddagger$ These authors contributed equally

\begin{abstract}
This paper presents several analogs of nucleic acids, including their structure and selected physico-chemical properties, reported recently as being obtained from non-nucleosidic units connected via phosphorodiester bonds. These analogs are built from units that instead of sugar residues carry different diol structures functionalized either with natural nucleobases or with other ring systems of an aromatic character. Some interesting nonnucleosidic oligonucleotide analogs and their applications are described. Unlocked (UNA) and glycerol nucleic acids (GNA) are also described.
\end{abstract}

Key words: nucleic acids, oligonucleotides, non-nucleosidic nucleic acids, UNA, GNA, oligonucleotide analogs

\section{Introduction}

In order to become useful as therapeutics, oligonucleotides and their analogs should (i) be able to bind effectively with target cellular RNAs (mRNAs), (ii) be resistant to hydrolysis by nucleases and other hydrolases, and (iii) be able to effectively cross the biological (cellular) membranes. The introduction of amine or intercalating residue(s) to an oligomer chain may modify its properties substantially. Oligonucleotides modified in such a way are not only able to interact with nucleic acids, but they can also either form specific or non-specific complexes with proteins, or serve as non-radioactive probes or markers. The interactions that are responsible for the modified properties include stacking interactions between the intercalating residues and nucleobases or coulombic forces. This might ease either diffusion through biological membranes, or the formation of complexes with target biomolecules - nucleic acids or proteins. The introduction of modifying residues often results in an increase in the resistance to hydrolytic enzymes.

\section{Acyclic analogs with nucleobases and their analogs with intercalating properties}

Acyclic nucleoside/nucleotide analogs with fluorescent residues are convenient diagnostic tools as well as probes to study the physical and structural properties of nucleic acids. These analogs do not contain sugar (ribose or 2'-deoxyribose) residue but rather a minimum fragment derived from glycerol.

Pedersen and co-workersvdescribed the synthesis of ( $S$ )-1-O-(4,4' -dimetoxytritylphenylomethyl)-3-O-(1pyrenylmethyl)glycerol phosphoramidite (1) (IPN, intercalating pseudo-nucleotide) - Figure 1 - that could be inserted into INA oligonucleotides (intercalating nucleic acid) via chemical synthesis of oligonucleotides (Christensen et al., 2002).

An oligonucleotide modified in this way has higher affinity to the complementary DNA strand (ssDNA) than to a single stranded RNA (ssRNA). The melting temperature $(\mathrm{Tm})$ of the derived duplex DNA/INA is $12.6^{\circ} \mathrm{C}$ higher than that of a corresponding RNA/INA (Table 1, entry 3). Christensen et al. observed that differentiation of the target ssDNA and ssRNA depends on the number of modifications introduced and their neighboring base pairs in the oligonucleotide (Christensen et al., 2002). The introduction of two IPN residues separated by four base pairs (Table 1 , entry 4 ) results in a $13.4^{\circ} \mathrm{C}$ increase in $\mathrm{Tm}$ in comparison with an unmodified duplex, while the difference between the hybridized DNA/INA and $\mathrm{RNA} / \mathrm{INA}$ increases to $25.8^{\circ} \mathrm{C}$.

An analysis of the thermodynamic data indicates that INA contacting oligonucleotides may be used for differentiating DNA/RNA chains (Filichev et al., 2004). 


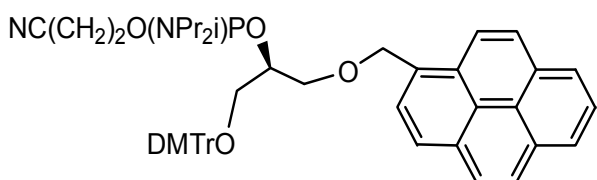

(S)-1-O-(4,4'-dimethoxytrityl)-3-O(1-pyrenylmethyl)glycerol phosphoramidite,1

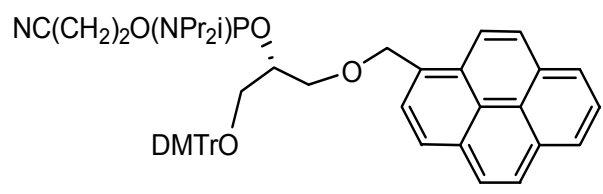

(R)-1-O-(4,4'-dimethoxytrityl)-3-O(1-pyrenylmethyl)glycerol phosphoramidite, 2

Fig. 1. Structure of the IPN phosphoramidite

Table 1. Melting temperatures (Tm) of duplexes with INA bulges

\begin{tabular}{|c|c|c|c|c|c|c|}
\hline S & Oligonucleotides & \multicolumn{2}{|c|}{$\begin{array}{c}\text { Target DNA } \\
\text { 5'-AGCTTGCTTGAG-3' }\end{array}$} & \multicolumn{2}{|c|}{$\begin{array}{c}\text { Target RNA } \\
\text { 5'-AGCUUGCUUGAG-3' }\end{array}$} & $\begin{array}{c}\text { Discrimination } \\
\operatorname{Tm}(\mathrm{DNA})-\operatorname{Tm}(\mathrm{RNA})\end{array}$ \\
\hline \multirow{2}{*}{1} & \multirow{2}{*}{$3^{\prime}$-TCGAACGAACTC- $5^{\prime}$} & $\operatorname{Tm}\left[{ }^{\circ} \mathrm{C}\right]$ & $\Delta \operatorname{Tm}\left[{ }^{\circ} \mathrm{C}\right]$ & $\operatorname{Tm}\left[{ }^{\circ} \mathrm{C}\right]$ & $\Delta \operatorname{Tm}\left[{ }^{\circ} \mathrm{C}\right]$ & $\Delta \operatorname{Tm}\left[{ }^{\circ} \mathrm{C}\right]$ \\
\hline & & 47.4 & - & 42.2 & - & 5.2 \\
\hline 2 & 3'-TCGAAC $_{\backslash_{\mathrm{G}}^{\prime}}$ GAACTC-5' $^{\prime}$ & 34.6 & -12.8 & 37.8 & -4.4 & -3.2 \\
\hline 3 & $3^{\prime}$-TCGAAC $\backslash_{X}{ }^{\text {GAACTC-5' }}$ & 50.4 & 3.0 & 37.8 & -4.4 & 12.6 \\
\hline 4 & $3^{\prime}$-TCGA $\left.\right|_{\mathrm{X}} / \mathrm{ACGA}_{\mathrm{X} /} \mathrm{ACTC}-5^{\prime}$ & 60.8 & 13.4 & 35.0 & -7.2 & 25.8 \\
\hline
\end{tabular}<smiles>COCCCOc1ccc2nc3c4ccccc4n(C)c3nc2c1</smiles>

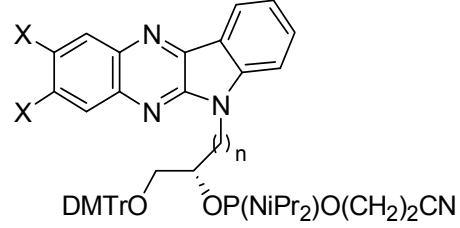

$$
\begin{aligned}
& 4 n=1, \mathrm{X}=\mathrm{H} \\
& 5 n=1, \mathrm{X}=\mathrm{Cl} \\
& 6 n=2, \mathrm{X}=\mathrm{H} \\
& 7 n=3, \mathrm{X}=\mathrm{H}
\end{aligned}
$$

\begin{tabular}{|c|c|c|c|c|c|c|c|}
\hline & \multirow{2}{*}{ Sequence } & \multirow{2}{*}{$\operatorname{Tm}\left[{ }^{\circ} \mathrm{C}\right]$} & 4 & 5 & 6 & 7 & 3 \\
\hline & & & $\Delta \operatorname{Tm}\left[{ }^{\circ} \mathrm{C}\right]$ & $\Delta \operatorname{Tm}\left[{ }^{\circ} \mathrm{C}\right]$ & $\Delta \operatorname{Tm}\left[{ }^{\circ} \mathrm{C}\right]$ & $\Delta \mathrm{Tm}\left[{ }^{\circ} \mathrm{C}\right]$ & $\Delta \operatorname{Tm}\left[{ }^{\circ} \mathrm{C}\right]$ \\
\hline $\begin{array}{l}\text { ODN1 } \\
\text { ODN2 }\end{array}$ & $\begin{array}{c}\text { 5'-AGCTTG - GTTGAG-3' } \\
\text { 3'TCGAACXCAACTC-5' }\end{array}$ & 49.6 & -9.0 & -8.3 & -1.0 & +1.7 & +4.5 \\
\hline $\begin{array}{l}\text { ODN3 } \\
\text { ODN4 }\end{array}$ & $\begin{array}{l}5^{\prime} \text {-AGCTTGXGTTGAG-3' } \\
3^{\prime} \text { TCGAAC - CAACTC-5' }\end{array}$ & 49.6 & -6.0 & -5.7 & -1.9 & +4.3 & -0.9 \\
\hline
\end{tabular}

Fig. 2. Structure of $6 \mathrm{H}$-indolo-[2,3- $b$ ]quinoxaline derivatives

Table 2. Melting temperatures of DNA duplexes with the INAs inserted as a bulge (Wamberg et al., 2006)

The synthesis of phosphoramidite 1 from the enantiomeric $(S)$-1-O-(4,4'-dimetoxytritylphenylomethyl)-3-O(1-pyrenylmethyl)glycerol and oligonucleotides containing this modification showed that of the two glycerol derivatives the INA derived from 1 form more stable duplexes than those derived from $\mathbf{2}$ (Table 2 ). Thus, it was concluded that intercalating nucleic acids with bulge insertions of ( $R$ )-1-O-(pyren-1-ylmethyl)glycerol have higher affinity for complementary ssDNAs than insertions of ( $S$ )-1-O-(pyren-1-ylmethyl)glycerol (Christensen et al., 2002, Filichev et al., 2004).

In subsequent studies those non-nucleoside analogs with higher affinity toward RNA were investigated (Wamberg et al., 2006). Derivatives of $6 \mathrm{H}$-indolo-[2,3- $b$ ] quino- 


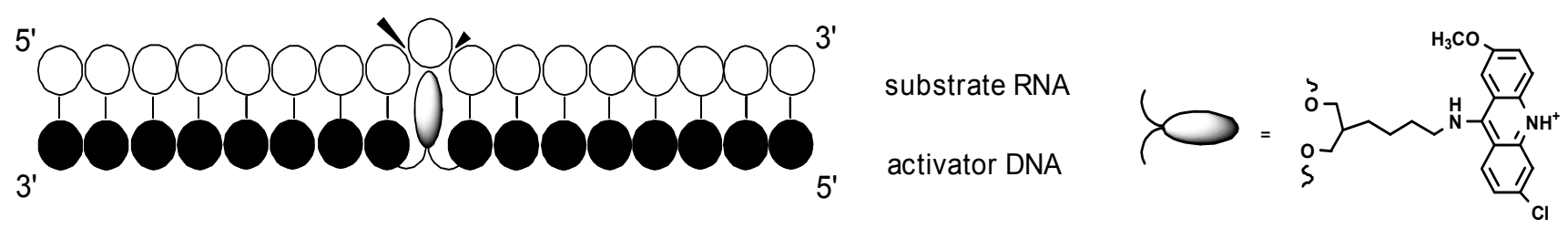

Fig. 3. Schematic representation of the artificial ribonuclease system. Selective scission sites are indicated by wedge-shaped arrows (Kuzuya et al., 2004)

RNA 1 5' UGA GAC GAU GAC UGG AUC UGG CAC UAC GAC ACU UGG 3' DNA ${ }_{1}-\mathbf{X}$ 3' ACT CTG CTA CTG ACC TAG XCC GTG ATG CTG TGA ACC 5'
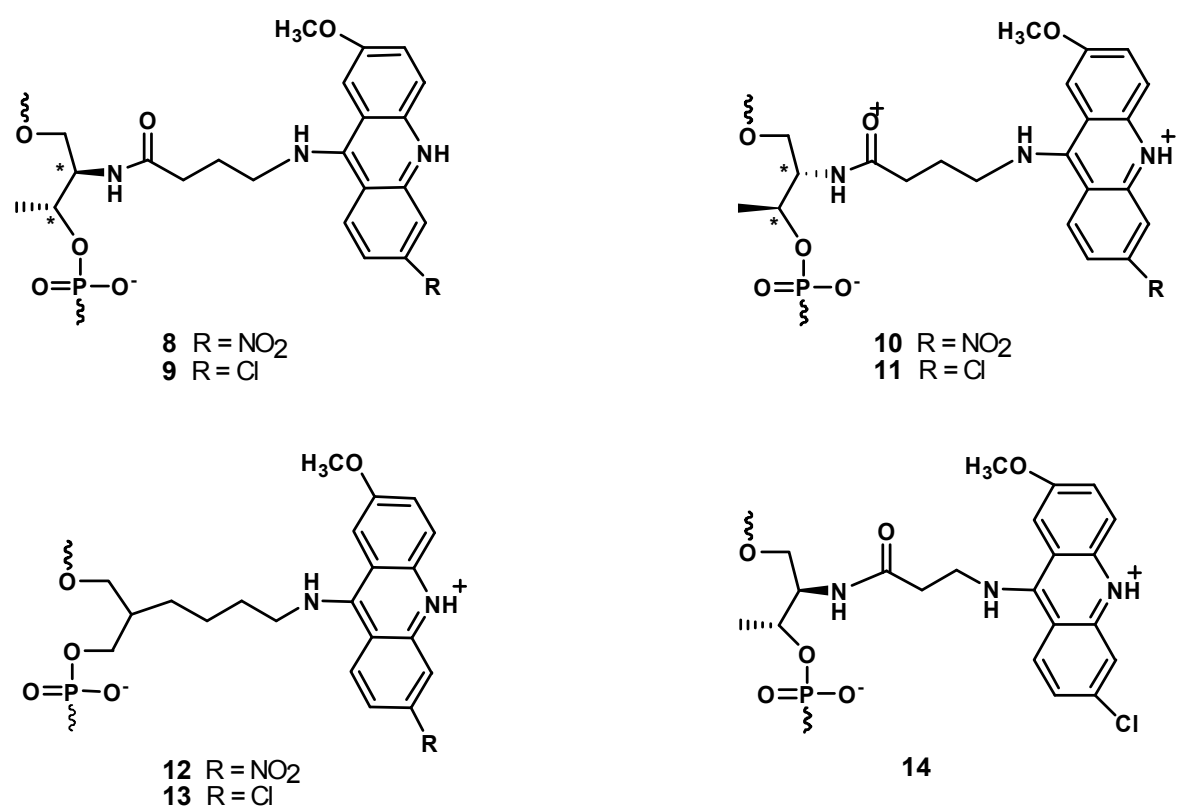

Fig. 4. Acridine derivatives inserted into oligonucleotides strands

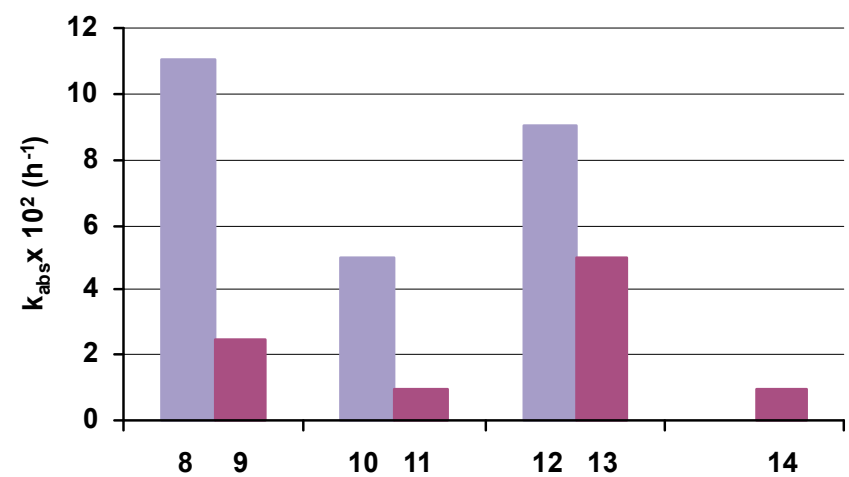

Fig. 5. Dependence of the RNA-activating ability of DNA-acridine conjugates on the structure of the linker (Shi et al., 2004)

xaline were obtained (Fig. 2). The influence of the length of linkers on the stability of DNA/DNA, DNA/RNA and DNA/LNA complexes was studied (Wamberg et al., 2006).
The data shown in Table 2 indicate that analogs with one or two carbons in the alkyl chain (4-6) lower the stability of DNA duplexes. The duplexes are stabilized when the alkyl chain contains more than two atoms (3 and $\mathbf{7})$. Moreover, a higher DNA duplex stability was observed when the intercalation occurred between two guanines rather than cytosine residues of the target DNA strand.

The next step studied DNA/RNA and DNA/LNA oligonucleotides bearing the intercalators (3-7) at the 5-end and in the middle of the strand and a higher duplex stabilization for the $\mathbf{3}$ and $\mathbf{7}$ analogs was observed. This observation is consistent with data obtained previously for DNA/DNA duplexes (see Table 2). Wamberg et al. concluded that a higher thermal stability is dependent on the length of the linkers. An appropriate linker length 

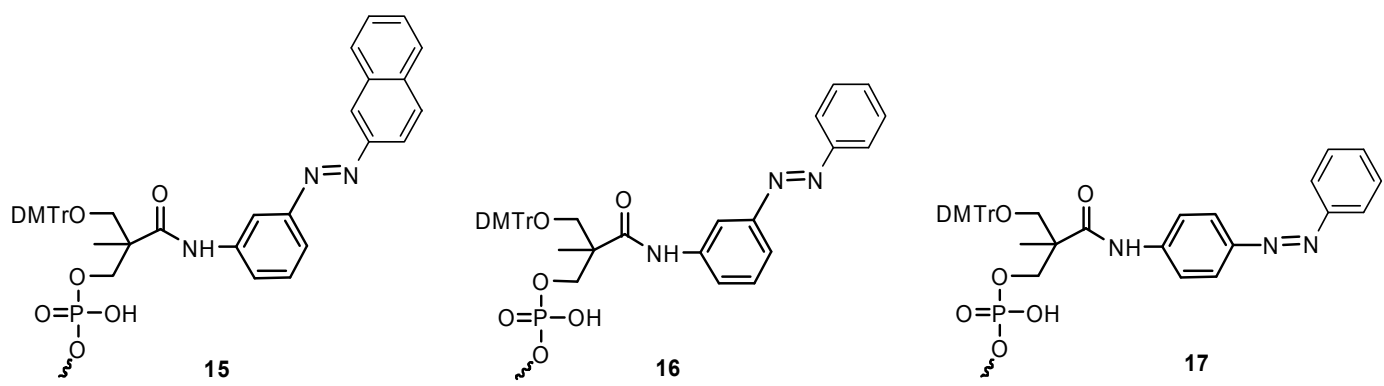

Fig. 6. Structure of azobenzene derivatives (Liang et al., 2001)

Table 3. Tm values of triplexes (Liang et al., 2001)

\begin{tabular}{c|c|c|c}
\hline \multirow{2}{*}{$\begin{array}{c}\text { Modified } \\
\text { oligonucleotides }\end{array}$} & \multicolumn{2}{|c|}{$\operatorname{Tm}\left[{ }^{\circ} \mathrm{C}\right]$} & \multirow{2}{*}{$\Delta \mathrm{Tm}\left[{ }^{\circ} \mathrm{C}\right]$} \\
\cline { 2 - 3 } & trans-form & cis-form & \\
\hline $15-\mathrm{T}_{13}$ & 45.5 & 5.0 & 40.5 \\
\hline $17-\mathrm{T}_{13}$ & 29.5 & 13.5 & 16.0 \\
\hline $16-\mathrm{T}_{13}$ & 30.2 & 10.7 & 19.5 \\
\hline
\end{tabular}

allows optimal base stacking within duplex structures (Wamberg et al., 2006).

Efficient regulation of a specific gene expression or RNA manipulation may be achieved via a sequence-selective cleavage of RNA. Selective activation of target phosphodiester linkages in the RNA results from the interaction with oligonucleotides bearing analogs of acridine (Fig. 3) (Kuzuya et al., 2004). This artificial ribonuclease selectively activates the phosphodiester linkage by conformational changes of the sugar ring of the unpaired nucleotide in the opposite strand.

As a result, an intramolecular nucleophilic attack by the 2 - $O$-atom of the ribose on the phosphorus atom is promoted. Hydrolysis of the selective linkage is more efficient with catalysts charged with $\mathrm{La}$ (III) or $\mathrm{Zn}$ (II) and $\mathrm{Mn}(\mathrm{II})$ ions. Due to the intercalating activity of the acridine residue in RNA, site-selective activation is completely "non-covalent" and other bonds in the oligonucleotide strand are not affected. A further study showed the dependence of the RNA-activating ability of ribonuclease on the acidity of acridine derivatives and the structure of the linkage attaching the acridine moiety (Kuzuya et al., 2002, Shi et al., 2004). Among DNA-acridine conjugates (Fig. 4) the highest activating ability was observed for the 9-amino-2-methoxy-6-nitroacridine (pKa 8.8). The higher acidity of $\mathbf{8 , 1 0}$ and $\mathbf{1 2}$ derivatives promotes efficient protonation of the phosphorus atom adjacent to the unpaired nucleotide increasing the site-selective hydrolysis.
The differences in the capacity for RNA activation depend on the structure of linkers. It was found that the most efficient derivatives were DNA-acridine conjugates with the L-threoninol residue $\mathbf{8}$ and the flexible tetramethylene alkyl chain $\mathbf{1 2}$ as linkers (Fig. 5). Additionally, the least favorable derivatives were $\mathbf{1 1}$ (from D-threoninol) and 14, possessing a rigid alkyl chain. Ribonuclease activity decreases (Fig. 5) due to the rigidity of the linker accompanied by the steric hindrance of aromatic acridine rings (Shi et al., 2004).

Photo-responsive molecules are used for the regulation of duplex and triplex formation and dissociation. The most popular is azobenzene residue, in particular its derivatives with the functional group attached in the para-position of the ring (e.g. $\mathrm{NH}_{2}, \mathrm{COOH}$ or $\mathrm{OH}$ ) (Asanuma et al, 2000, Liang et al., 2001). However, due to the rapid temperature-induced cis-transisomerization of parasubstituted forms (17), the meta-position makes it possible to control the thermal durability of cis-azobenzene derivatives (Fig. 6).

The azobenzene modifications allow for the regulation of the formation and dissociation of double- and triple-stranded structures. Triplex formation may result in cis-trans isomerization of meta-azobenzene derivatives tethered to the third strand of oligonucleotides. The trans-aminoazobenzene plane system (16) stabilizes the triple helix by stacking interactions. Introduction of a cis-form affects triplex destabilization by induction of a steric hindrance. Moreover, the ability of modified strands to hybridize with the target duplex decreases (Table 3).

It transpired that effective photo-regulation could be achieved by the introduction of polyaromatic residues to the oligomer. In particular, incorporation of phenylazonaphthalene residue (15) into the triplex increases the durability of its trans-form and the stability of the complex by $40^{\circ} \mathrm{C}$ (Table 3 ). 

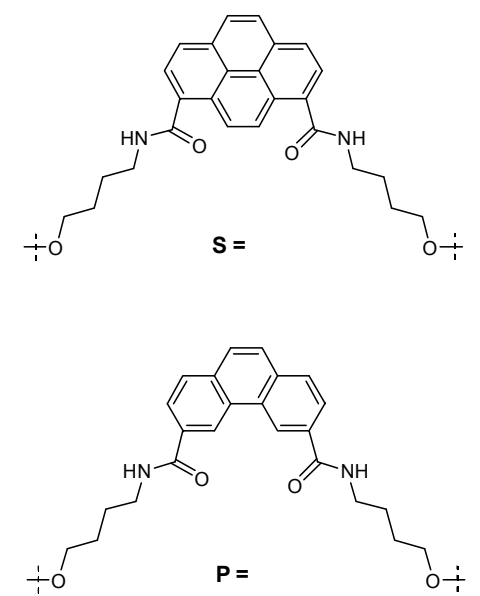
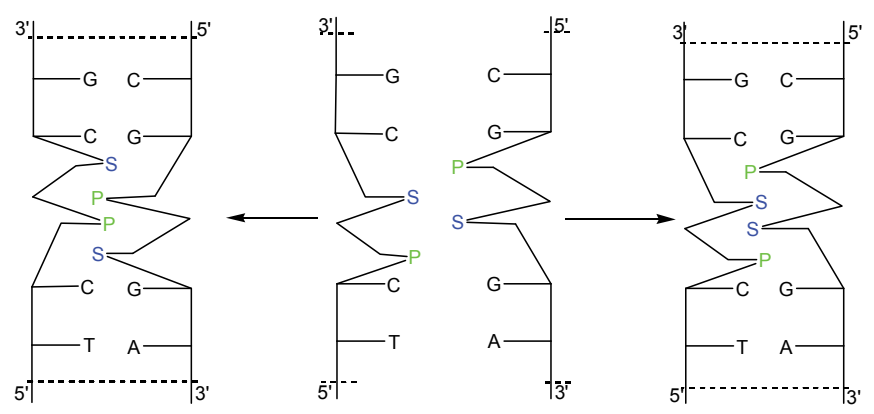

Fig. 7. Possible interstrand-stacking arrangements of unequal pairs of phenanthrene $(\mathbf{P})$ and pyrene $(\mathbf{S})$ building blocks (Langenegger et al., 2006)

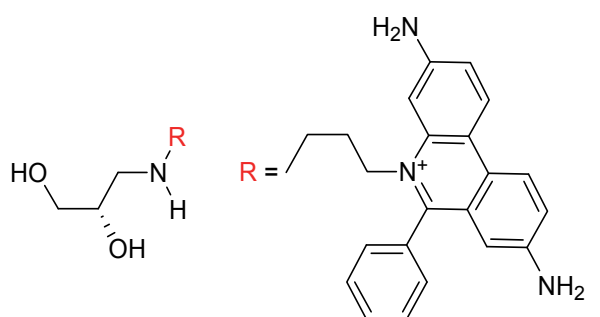

18

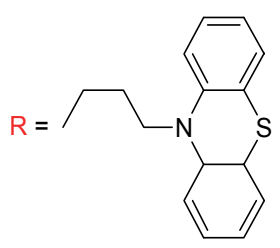

19

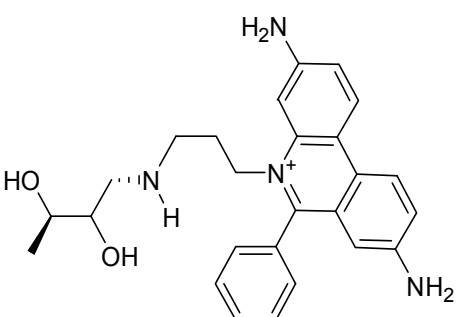

20

Fig. 8. Structures of $(S)$-aminopropanediol linked ethidium 18 and phenothiazine 19, and ( $S$ )-threoninol linked ethidium 20 (Schmucker et al., 2012)<smiles></smiles><smiles>CN1/C(=C\c2cc[n+](CCCOC(=O)NC[C@H](O)CO)c3ccccc23)Sc2ccccc21</smiles>

23<smiles>CN1/C(=C\C=C\c2cc[n+](CCCOC(=O)NC[C@H](O)CO)c3ccccc23)Sc2ccccc21</smiles>

25<smiles>C[n+]1ccc(/C=C2\Sc3ccccc3N2CCCOC(=O)NC[C@@H](O)CO)c2ccccc21</smiles>

22<smiles>C[n+]1ccc(/C=C/C=C2\Sc3ccccc3N2CCCOC(=O)NC[C@H](O)CO)c2ccccc21</smiles>

24

Fig. 9. Non-nucleosidic fluorescent DNA base substitutes: 21 (BODIPY), 22/23 (thiazole orange), and 24/25 (thiazole red) (Schmucker et al., 2012) 
Table 4. Melting temperatures of chromophores (Schmucker et al., 2012)

\begin{tabular}{c|c|c|c}
\hline Modification & Sequence & $\operatorname{Tm}\left[{ }^{\circ} \mathrm{C}\right]$ & $\Delta \operatorname{Tm}\left[{ }^{\circ} \mathrm{C}\right]$ \\
\hline 21 & & 63.3 & $-7.4^{\mathrm{a}}$ \\
\hline 22 & & 68.6 & $-2.1^{\mathrm{a}}$ \\
\hline 23 & $3^{\prime}-\mathrm{GXG}-5^{\prime}$ & 68.4 & $-2.3^{\mathrm{a}}$ \\
\hline 24 & $5^{\prime}-\mathrm{CCC}-3^{\prime}$ & 65.7 & $-5.0^{\mathrm{a}}$ \\
\hline 25 & & 66.2 & $-4.5^{\mathrm{a}}$ \\
\hline
\end{tabular}

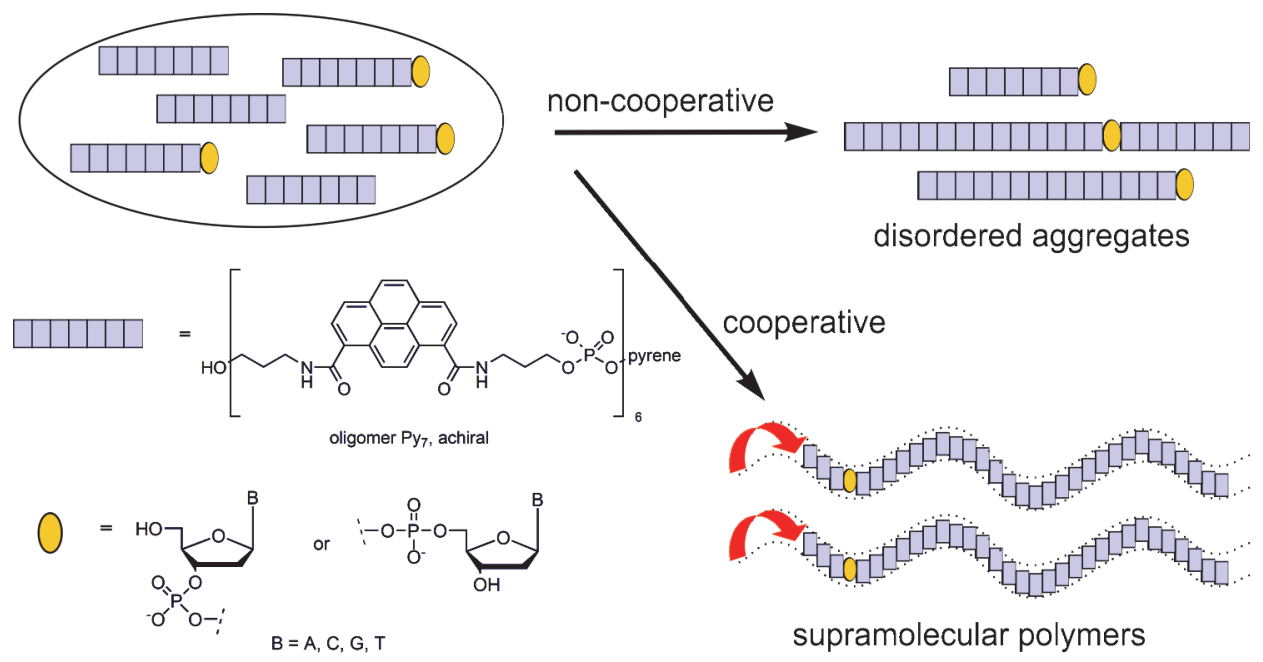

Fig. 10. Influence of single nucleotides on the aggregation of oligomers (Nussbaumer et al., 2012)

Synthetic non-isotopically labeled oligonucleotides are widely used for sequencing and medical diagnostics, and as probes in molecular biology. Structural modifications of the nucleotide units facilitate the delivery of the nucleic acid into the cells or increase their enzymatic resistance (Guzaev et al., 1996). Langenegger described (Langenegger et al., 2006) synthesis and spectroscopic studies of DNA duplexes that were modified with structurally similar but electronically disparate molecules, e.g. pyrene $\mathbf{S}$ and phenanthrene $\mathbf{P}$ (Fig. 7).

As a result of the above, the placement of nucleosides residues in both an interstrand pyrene and phenanthrene residues makes it possible to observe differences in the spectroscopic properties of the modified duplexes. In the model in which the interaction between pyrene moieties is assumed, the strong absorption (or emission) that is characteristic of pyrene excimer was observed. Furthermore, the interstrand-stacking interactions between the polyaromatic residues take place and can be observed with a high degree of selectivity in pyrene-pyrene but not phenanthrene-phenanthrene analogs (Langenegger et al., 2006). This allows the design of DNA hybrids with interesting spectroscopic properties by selecting the places of incorporation of polyaromatic building blocks. Oligonucleotides modified by non-nucleosidic residues can be used for the creation of nanomaterials or as fluorescent probes used for diagnostic purposes.

To develop artificial functionalities of DNA the oligonucleotide 2 -deoxyribose residue was replaced with an acyclic linker (Schmucker et al., 2012). The linker was to provide a higher thermal DNA stability and appropriate flexibility of the chromophore to intercalate. The ethidium residue was attached as a linker to the (S)-1-amino1,3-propanediol (18) and (S)-threoninol (20) and their affinity for DNA stacking ability was investigated (Fig. 8).

Tm values of modified DNA showed a minor influence of the structure of acyclic linkers $(\mathbf{1 8}, \mathbf{2 0})$ on chromophore intercalation. Moreover, the stability was only slightly higher in comparison to the unmodified DNA double strand. As an alternative, DNA nucleoside 


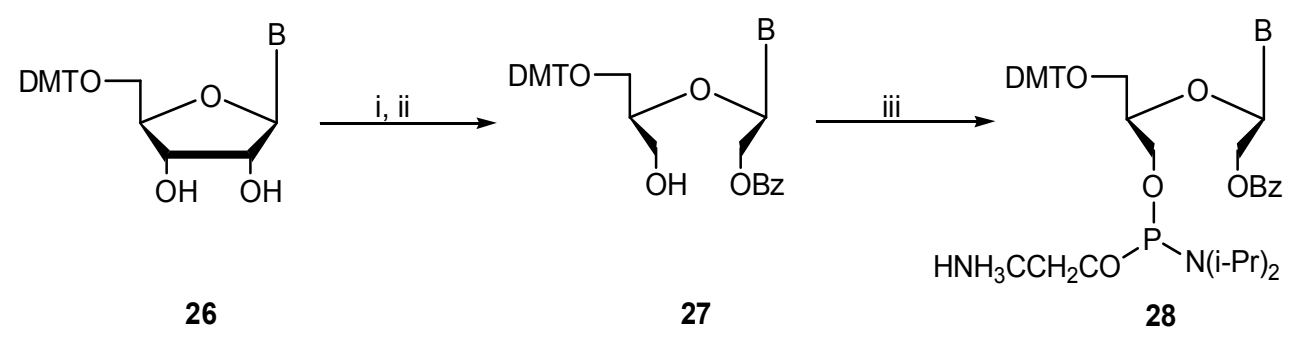

Fig. 11. Synthesis of UNA phosphoramidites from $5^{\prime}$-O-dimethoxitrytylribonucleosides (DMT $=4,4^{\prime}$-dimetoxytrityl, B = Ura, Thy or a protected nucleobase residue): (i) periodate oxidation; (ii) benzoylation and separation of $2^{\prime}$-O-Bz-isomers; (iii) phosphitylation
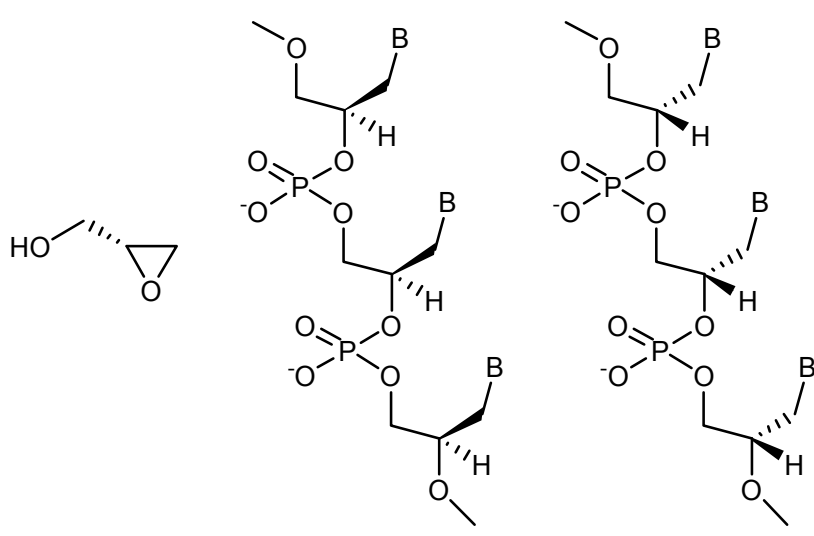

Fig. 12. Structure of $(R)-(-)$-glycidol and $(R)$-GNA and yields $(S)$-GNA (Zhang et al., 2005)

substitute containing (S)-1-amino-1,3-propanediol was incorporated into the oligonucleotide strand. Duplex sets modified with ethidium (18) and phenothiazine (19) derivatives showed very similar stabilities. It was concluded that the intercalations do not vary with the type of “counterbase" (Schmucker et al., 2012).

Loudet and Burgess described an interesting approach using oligonucleotides modified by BODIPY (21) and cyanine dyes (22-25) (Mishra, et al., 2000) and studied their fluorescent properties (Loudet and Burgess, $2007)$. For this purpose, thiazole orange $(\mathbf{2 2}, \mathbf{2 3})$ and thiazole red $(\mathbf{2 4}, \mathbf{2 5})$ containing $(S)$-1-aminopropane-2,3diol linker attached either to the quinoline nitrogen or to the thiazole nitrogen was inserted into oligonucleotide strands (Fig. 9).

Both thiazole dyes, 22 and 23, marginally destabilized the duplex (Schmucker et al., 2012). The same effect for thiazole red dyes, $\mathbf{2 4}$ and $\mathbf{2 5}$, was observed (Table 4). These data indicate that stacking stability was regained by chromophores (Schmucker et al., 2012).
Moreover, the spectral properties for all modified oligonucleotides differed only slightly (Table 4 ). Among the tested dyes only $\mathbf{2 2}$ and $\mathbf{2 4}$ constituted a pair for energy transfer with the potential to be applied as molecular beacons and for fluorescence imaging to monitor DNA/RNA delivery (Holzhauser et al., 2010, Holzhauser and Wagenknecht, 2011).

A great advantage of DNA molecules are their selfassembling properties. The well-defined arrangement of the building blocks allows construction of large assemblies in a predictable manner. Not surprisingly, the use of nucleic acids as a versatile scaffold for construction of different types of materials is increasing. The formation of supramolecular polymers from the achiral heptapyrenotide (Py7) and its mono- and di-modified nucleotide derivatives was investigated (Fig. 10) (Nussbaumer et al., 2012). In these constructs the DNA was used as the scaffold for the structural organization. Py7 co-aggregation with nucleotide-modified oligonucleotides assembled via a nucleation-elongation mechanism which is characteristic for supramolecular polymers. Moreover, during polymerization Nussbaumer et al. observed a chiral amplification for pyrene oligomers containing a single nucleotide modification.

On the other hand, self-aggregation nucleotide-modified pyrenotides followed an isodesmic mechanism. These modified molecules represent a new type of oligomeric building block that may be used for construction of optically active polymeric materials (Nussbaumer et al., 2012).

An elegant and convenient synthesis of nucleic acid analogs, so called unlocked nucleic acids (UNA), was described by Wengel and co-workers (Nielsen et al., 1995; 2009). UNA monomers derived from ribonucleosides via oxidative cleavage of a C-C bond of a $2^{\prime}, 3^{\prime}$-cis-diol sy- 
stem, followed by borohydride reduction of aldehyde groups, were then transformed into appropriately protected phsosphoramidites (Nielsen et al., 1995, Langkjaer et al., 2009) (Fig. 11).

UNA acids can be regarded as unlocked RNA (Langkjaer et al., 2009). These analogs are conformationally extremely flexible; in contrast to so-called Locked $\mathrm{Nu}$ cleic Acids (LNA) (Koshkin et al., 1998) that contain furanose residues locked in a C3'-endo conformation and are considered to be locked RNA (Langkjaer et al., 2009). Structural studies have shown that LNA oligonucleotides induce A-type (RNA-like) duplex conformations (Vester and Wengel, 2004).

UNA modifications have been shown to decrease the thermal stability of a full-matched duplex and generally the loss of thermal stability is lower if modifications are present near (1-3 bases) the end of a duplex and may cause only a $1-3^{\circ} \mathrm{C}$ drop in the Tm (Pasternak and Wengel, 2010). When UNA was tested in a combination of 2160 siRNA duplexes it was found to increase the silencing effect while remaining non-toxic to HeLa cells and being able to incorporate effectively into both the sense and antisense strands of the siRNAs (Bramsen et al., 2009).

The UNA skeleton is a useful carrier of modifications that can be effectively linked to 2 '-position. The derivatives with a piperazine group (Karlsen et al., 2009; Karlsen et al., 2012) are among the possible linkers of useful ligands, including a terpyridine ligand for metal chelation (Karlsen et al., 2009; Karlsen et al., 2012).

Another interesting type of non-nucleosidic analogs of nucleic acids, i.e. glycol nucleic acid (GNA), has been recently developed by Meggers and co-workers (Zhang et al., 2005; Zhang et al., 2006). Commercially available $(R)-(+)$ - and $(S)-(-)$-glycidol were used as substrates to prepare $(S)$-GNA, and $(R)$-GNA, respectively (Fig. 12).

Meggers and his team demonstrated that the derived GNA duplexes considerably exceed the thermal stabilities of analogous DNA duplexes (Zhang et al., 2005; Zhang et al., 2006). Their structure and dynamics have been extensively studied and have shed an interesting light on a possible biological function of different NA analogs (Schlegel et al., 2010; Johnson et al., 2011). The discovery of a pronounced twisting/untwisting mode of dsGNA may play an important role in the high thermodynamic stability of GNA. It also hints why the simplest form of a duplex-forming nucleic acid currently known has not been chosen by life (Schlegel et al., 2010).

\section{References}

Asanuma H., Xingguo L., Makoto K. (2000) Meta-aminoazobenzene as a thermo-insensitive photo-regulator of DNAduplex formation. Tetrahedron Lett. 41: 1055-1058.

Bramsen J.B., Laursen M.B., Nielsen A.F., Hansen T.B., Bus C., Langkjaer N., Babu B.R. et al. (2009) A large-scale chemical modification screen identifies design rules to generate siRNAs with high activity, high stability and low toxicity. Nucl. Acids Res. 37: 2867-2881.

Christensen U.B., Pedersen E.B. (2002). Intercalating nucleic acids containing insertions of 1-O-(1-pyrenylmethyl)glycerol: Stabilisation of $d s D N A$ and discrimination of DNA over RNA. Nucl. Acids Res. 30: 4918-4925.

Filichev V.V., Hilmy K.H.M, Christensen U.B., Pedersen E.B. (2004) Intercalating nucleic acids: the inversion of the stereocenter in 1-O-(pyren-1-ylmethyl)glycerol from $R$ to $S$. Thermal stability towards ssDNA, ssRNA and its own type of oligodeoxynucleotides. Tetrahedron Lett. 45: 4907-4910.

Guzaev A., Salo H., Azhayev A., Lönnberg H. (1996). Novel nonnucleosidic building blocks for the preparation of multilabeled oligonucleotides. Bioconjugate Chem. 7: 240-248.

Holzhauser C., Berndl S., Menacher F., Breunig M., Göpferich A., Wagenknecht H.A. (2010) Synthesis and optical properties of cyanine dyes as fluorescent DNA base substitutions for live cell imaging. Eur. J. Org. Chem. (2010): 1239-1248.

Holzhauser C., Wagenknecht H.A. (2011) In-stem-labeled molecular beacons for distinct fluorescent color readout. Angew. Chem. Int. Ed. 50: 7268-7272.

Johnson A.T., Schlegel M.K., Meggers E., Essen L.O., Wiest O. (2011) On the structure and dynamics of duplex GNA. J. Org. Chem. 76: 7964-7974.

Karlsen K.K., Jensen T.B., Wengel J. (2009) Synthesis of an unlocked nucleic acid terpyridine monomer and binding of divalent metal ion in nucleic acid duplexes. J. Org. Chem. 74: 8838-8841.

Karlsen K.K., Pasternak A., Jensen T.B., Wengel J. (2012) $P y$ rene-modified unlocked nucleic acids: synthesis, thermodynamic studies, and fluorescent properties. ChemBiochem. 13: 590-601.

Koshkin A.A., Singh S.K., Nielsen P., Rajwanshi V.K., Kumar R., Meldgaard M., Carl Erik Olsen C.E., Wengel J. (1998) LNA (Locked Nucleic Acids): synthesis of the adenine, cytosine, guanine, 5-methylcytosine, thymine and uracil bicyclonucleoside monomers, oligomerisation, and unprecedented nucleic acid recognition. Tetrahedron 54: 3607-3630.

Kuzuya A., Zhou J.M., Komiyama M. (2004) DNA, PNA, and their derivatives for precise genotyping of SNPS. MiniRev. Org. Chem. 1: 125-131.

Kuzuya A., Machida K., Komiyama M. (2002) A highly acidic acridine for efficient site-selective activation of RNA leading to an eminent ribozyme mimic. Tetrahedron Lett. 43: 8249-8252.

Langenegger S.M, Häner R. (2006) Selectivity in DNA interstrand-stacking. Bioorg. Med. Chem. Lett. 16: 5062-5065.

Langkjaer N., Pasternak A., Wengel J. (2009) UNA (unlocked Nucleic Acid): a flexible RNA mimic that allows engine- 
ering of nucleic acid duplex stability. Bioorg. Med. Chem. 17: 5420-5425.

Liang X., Asanuma H., Komiyama M. (2001) Phenylazonaphthalene as a superb photo-regulator for DNA-triplex formation. Tetrahedron Lett. 42: 6723-6725.

Loudet A., Burgess K. (2007) BODIPY dyes and their derivatives: syntheses and spectroscopic properties. Chem. Rev. 107: 4891-4932.

Mishra A., Behera R.K., Behera P.K., Mishra B.K., Behera B.K. (2000) Cyanines during the 1990s: a review. Chem. Rev. 100: 1973-2012.

Nielsen P, Dreiře L.H., Wengel J. (1995) Synthesis and evaluation of oligodeoxynucleotides containing acyclic nucleosides: introduction of three novel analogues and a summary. Bioorg. Med. Chem. 3: 19-28.

Nussbaumer A.L, Samain F., Malinovskii V.L., Häner R. (2012) Supramolecular polymerization of oligopyrenotides - control by single, natural nucleotides. Org. Biomol. Chem. 10: 4891-4898.

Pasternak A., Wengel J. (2010) Thermodynamics of RNA duplexes modified with unlocked nucleic acid nucleotides. Nucleic Acids Res. 38: 6697-6706.
Schlegel M.K, Essen L.O., Meggers E. (2010) Atomic resolution duplex structure of the simplified nucleic acid GNA. Chem. Commun. 46: 1094-1096.

Schmucker W., Wagenknecht H.A. (2012) Organic chemistry of DNA functionalization; chromophores as DNA base substitutes versus DNA base/2 - modifications. Synlett. 23: 2435-2448.

Shi Y., Kuzuya A., Machida K., Komiyama M. (2004) Crucial role of linker portion in acridine-bearing oligonucleotides for highly efficient site-selective RNA scission. Tetrahedron Lett. 45: 3703-3706.

Vester B., Wengel J. (2004) LNA (locked Nucleic Acid): Highaffinity targeting of complementary RNA and DNA. Biochemistry 43: 13233-13241.

Wamberg M.C., Hassan A.A., Bond A.D., Pedersen E.B. (2006) Intercalating nucleic acids (INAs) containing insertions of 6H-indolo[2,3-b]quinoxaline. Tetrahedron 62: 11187-11199.

Zhang L., Peritz A.E., Meggers E. (2005) A simple glycol nucleic acid. J. Amer. Chem. Soc. 127: 4174-4175.

Zhang L., Peritz A.E., Carroll P.J., Meggers E. (2006) Synthesis of glycol nucleic acids. Synthesis: 645-653. 